HID 48 (2021)

\title{
PRÁCTICAS DE ORGANIZACIÓN Y CONSERVACIÓN DOCUMENTAL DEL CABILDO DE LA CATEDRAL DE OPORTO. (DE LA EDAD MEDIA HASTA EL FINAL DEL ANTIGUO RÉGIMEN) ${ }^{1}$
}

\author{
ORGANIZATION AND CONSERVATION PRACTICES OF THE \\ CHAPTER OF THE PORTO SEE. (FROM THE MIDDLE AGES \\ TO THE END OF THE ANCIENT REGIME)
}

Maria Joẽo Oliveira e Silva

Universidade do Porto

mjpinho@letras.up.pt ORCID: https://orcid.org/0000-0002-9104-5241

RESUMEN: El objetivo de este artículo es el estudio del archivo del cabildo de la Catedral de Oporto y sus prácticas de organización y conservación documental, desde el periodo medieval hasta el final del Antiguo Régimen. Para ello, se cruzarán dos realidades: la práctica y la teórica. La primera, verificada en documentos de diversa naturaleza, así como en ciertos instrumentos de acceso a la información producidos por el cabildo. La segunda se recogió a partir de las Constituciones Sinodales de la diócesis de Oporto, promulgadas por los obispos como consecuencia de la realización de los sínodos. También se han observado los diversos cambios de ubicación que tubo el archivo dentro del espacio catedralicio y se ha cuestionado la relación entre el archivo capitular y el archivo de la mitra a lo largo de la cronología contemplada.

PAlabras Clave: Catedral de Oporto; cabildo; archivo; prácticas de archivo; inventarios.

ABSTRACT: The aim of this article is to study the archive of the chapter of the Porto See, its practices of organization and documentary conservation, from the medieval period to the end of the Old Regime. To this end, two realities will be crossed: the practical and the theoretical. The first was detected in the documentation of varied nature and in certain instruments of access to information produced by the chapter. The second was taken from the Synodal Constitutions of

Recibido: 29-1-2021; Aceptado: 4-3-2021; Versión definitiva: 9-3-2021

1. In memoriam Professor Pe. José Marques

Copyright: (C) Editorial Universidad de Sevilla. Este es un artículo de acceso abierto distribuido bajo los términos de la licencia de uso y distribución Creative Commons Reconocimiento-NoComercialSinObraDerivada 4.0 (CC BY-NC-ND 4.0) 
the diocese of Porto, ordered by the bishops following the holding of synods. The various changes in the location of the archive within the cathedral space will also be observed, as well as the relationship between the capitular archive and the miter archive will be considered throughout the analyzed chronology.

KEYWORDS: See of Porto; chapter; archive; archival practices; inventories.

\section{INTRODUCCIÓN}

Entre 1112 e 1114, con la restauración de la diócesis de Oporto, comenzó un proceso gradual de estructuración interna del que hizo parte la creación de un organismo responsable por la producción documental, o sea, la cancillería de la Catedral. De esta necesidad surgieron otras directamente relacionadas con ella, como la preservación de los documentos, la organización de los espacios destinados a su conservación, la elección de los encargados de custodiarlos y la definición de prácticas adecuadas para su gestión. En suma, se trataba de estructurar el archivo documental catedralicio. A su vez, la evolución de los diversos organismos diocesanos implicó la formación de archivos específicos agregados a cada uno de ellos. En este artículo concentraremos la atención en el archivo del cabildo, cuya historia se cruza con otros archivos diocesanos pero que debe ser estudiado de forma independiente ${ }^{2}$. Tendremos en cuenta dos puntos de análisis: el práctico y el teórico. El práctico fue observado a través de las informaciones recogidas en documentación de diversa índole, así como en determinados instrumentos de acceso a la información que fueron producidos por el cabildo. La teórica fue recogida en la legislación promulgada por los obispos, en su mayoría, consecuencia de la realización de sínodos diocesanos, es decir, en las Constituciones Sinodales ${ }^{3}$, también ellas influenciadas directamente por las medidas impuestas por las normativas pontificales anteriores y posteriores al Concilio de Trento ${ }^{4}$. El objetivo es cruzar las dos realidades y acompañar la evolución del archivo capitular desde la Edad Media hasta el principio del siglo XIX.

\section{LA ORGANIZACIÓN/CONSERVACIÓN DE LOS DOCUMENTOS}

\section{EN EL PERIODO MEDIEVAL}

La referencia más antigua concerniente a la realización de un sínodo en la diócesis de Oporto remonta al episcopado de Julião Fernandes (1247-1260), aunque

2. Como afirma Fernanda Ribeiro: "As mais das vezes vemos serem considerados como arquivos distintos, o da Mitra (ou Bispado), o da Cúria diocesana, o da Câmara Eclesiástica e outros, como se de instituições independentes se tratasse... Por outro lado, vemos também serem tratados como arquivos diocesanos os que provêm dos Cabidos das catedrais e que, na verdade, não podem ser misturados com os primeiros". Ribeiro 2003, p. 289.

3. Sobre las Constituciones Diocesanas véase Paiva 2000, pp. 9-15.

4. Sobre esta cuestión véase García y García 1997, pp. 31-37. 
no es posible atribuirle una fecha concreta ${ }^{5}$. Después de este y hasta finales del siglo XV se habrán realizado por lo menos ocho reuniones sinodales de las cuales se conservan algunas noticias y, en algunos casos, ciertas constituciones aprobadas $^{6}$. Sin embargo, en ninguno de los textos recogidos se hace referencia al archivo (ni al del cabildo ni a ningún otro) ni al modo de guardar o inventariar la documentación perteneciente a la canónica. Es decir que, si existió una normativa diocesana relacionada con este tema no es posible tener conocimiento de ella actualmente.

La ausencia de una "teoría" lleva a la búsqueda de respuestas en la "práctica". En ese sentido resultan importantes las referencias recogidas en las fechas tópicas de los documentos. En varios casos se refieren redacciones hechas en el tesoro de la Catedral, como en el caso de una donación de 1379, escrita no logo hu soiha de seer o tesouro e ora chamam o cabidoo novo ${ }^{7}$. Este cabildo estaría localizado en el claustro gótico, adyacente a la actual sacristía. Incluso desconociendo la localización concreta del archivo en el edificio de la Catedral durante este periodo, es probable que, tal como sucedió en diversas instituciones eclesiásticas, episcopales y monásticas, se situase in tesauro ${ }^{8}$. Es decir, es posible que el lugar de "hacimiento" del documento pueda coincidir con el lugar de su conservación. También se sabe que el archivo podría haber compartido el espacio con el armarium o biblioteca, tal y como lo certifica el hecho de que, en 1307, el cabildo mandase depositar duo publica instrumenta (...) in biblioteca ${ }^{9}$, siendo esta la referencia más antigua al lugar donde se guardaban/conservaban los documentos de la Catedral.

La escasez de datos relativos a la localización del archivo capitular se repite en lo concerniente al acondicionamiento de sus actos escritos. Arcas, huchas, cajas, cofres y escaños eran los lugares más comunes para la conservación tanto de libros y documentos como también de otros bienes considerados valiosos, tales como reliquias, paramentos y diversos ornamentos ${ }^{10}$. Se sabe que a finales del siglo XIV había un cierto clérigo cuya función específica era guardar el tesoro ${ }^{11}$

5. Synodicon Hispanum. II - Portugal 1982, p. 344.

6. Nos referimos a los sínodos de Vicente Mendes, realizado en fecha desconocida entre $1261 \mathrm{y}$ 1265, de João Gomes, en 1326, de Pedro Afonso, en 1344, de Afonso Pires, en 1360 y en 1371, de João Esteves de Azambuja, sin fecha concreta, entre 1391 y 1399, de Antão Martins de Chaves, en 1430 y de João de Azevedo, también realizado en fecha incierta entre 1465 y 1495 . Sobre todos eles véase Synodicon Hispanum. II - Portugal 1982, pp. 343-354.

7. Arquivo Distrital do Porto, Cartório do Cabido, Livros dos Originais, 1678, f. 23.

8. Sobre la tesorería como lugar de conservación de documentos en varias instituciones eclesiásticas portuguesas véase, por ejemplo, Costa 1980, pp. 11-12; Cunha 2005, pp. 112-114; Gomes 2007, pp. 260-262.

9. ADP, Mitra, Pergaminhos, doc. 13

10. Como afirma Michael Clanchy:" Documents, books, relics of the saints and jewellery were not usually kept in places distinct from each other, because they were often physically joined together, and the difference between writings and other precious objects was not as obvious as it is to a modern literate". Clanchy 1993, p. 155. Sobre la conservación documental en general y en particular sobre las piezas de mobiliario en las instituciones portuguesas véase Santos, 1994, pp. 26-31 y Santos, 2001, pp. 237-242.

11. En 1390, Gonçalo Eanes, clérigo de lo tesoro, fue testigo de una posesión de bienes inmuebles perteneciente al cabildo - ADP, Cartório do Cabido, Livros dos Originais, 1667, f. 441. El mismo 
donde existían diversos cofres usados para depositar documentos, aunque también para otros fines. De hecho, en 1398, el Rey João I, el obispo João y el cabildo de la Catedral de Oporto establecieron un acuerdo por medio del cual el Rey se comprometía a efectuar el pago de una determinada cantidad de dinero, que sería guardada dentro de huuma arrca (sic) de duas chaves a qual este dentro no tesouro da dicta Eigreja [de Oporto] ${ }^{12}$. Los encargados de las dos llaves fueron João Afonso Aranha, (canónigo de la Catedral e intendente de la Hacienda Real en 1398 y $1401)^{13}$ y Fernão Domingues Borralho (clérigo de ordenes menores e intendente de la fundición de las monedas del Rey en Oporto entre 1390 y 1391) ${ }^{14}$. Parece que la elección de estos dos hombres no fue aleatoria: ambos eran miembros del clero, así como oficiales regios en determinado momento, un hecho que les granjeo la confianza tanto del Rey como del Obispo.

Como se podrá verificar, han sido encontradas referencias a la biblioteca y a lo tesouro de la Catedral que datan del siglo XIV. Es probable que el término 'cartório' se utilizase también desde ese periodo o inclusive, antes, aunque las primeras referencias apenas se encuentran en la segunda mitad de la centuria siguiente, en una entrada del Livro dos legados, missas e anniversarios que he obrigado satisfazer o Reverendo Cabido o Datário, nombre por el cual es más conocido ${ }^{15}$. Este libro no tiene una fecha exacta, aunque fue producido durante el episcopado de João de Azevedo (1465-1495) ${ }^{16}$, registrando sucesivas entradas a lo largo de varias centurias. La entrada en cuestión es la siguiente:

Em este dia [16 de septiembre] ha o cabidoo de fazer huum anyverssayro pola alma de Luis Affomso das Eyras cidadãao (...) e por este annyverssayro ha d'aver o cabido III morabitinos velhos pellas casas da Baynharya as quaaes forom vendidas com o dito foro a Diego Perez <Selleyro $>$ segundo se contem em huma scriptura que jaz no cartayro $(. . .)^{17}$.

También en el Datário se encuentra la referencia más antigua al Censual do Cabido $^{18}$, nombre por el cual se conoce el códice medieval que contiene dos libros

Gonçalo Eanes surge de nuevo en 1392, también como testigo de una posesión, siendo referido como $O$ que guarda o tesouro da See - ADP, Cartório do Cabido, Livros dos Originais, 1688, f. 2v.

12. Referida en 1398. ADP, Cartório do Cabido, Livros dos Originais, 1673, f. 23.

13. Sobre el ejercicio de esta y de otras funciones en la corte regia y en la consejería de la ciudad de Oporto véase Homem 1982, pp. 7-14.

14. Fui nombrado Juez del Consejo el 3 de julio de 1390. Vereaçoens. Anos de 1390-1395 s/ ano, ff. 12-14. Véase una breve biografía de Fernão Domingues Borralho en Ferraz 2008, pp. 250-253.

15. ADP, Cartório do Cabido, 1574.

16. Probablemente en 1470 , según se deduce de una entrada registrada el día 15 de octubre: "Ordenou o cabidoo que d'oje en deante as rendas $<$ das $>$ capeelas se recadem (...) E esto foy assy ordenado no anno de mil CCCCLXX” - ADP, Cartório do Cabido, 1574, f. 73v.

17. ADP, Cartório do Cabido, 1574, fl 66. El referido documento todavía se conserva en el Cartório do Cabido con la cota ADP, Cartório do Cabido, Livros dos Originais, 1676, f. 32.

18. Una de las entradas referentes al día 8 de noviembre dice lo siguiente: "Annyverssayro pelo bispo Dom Fernando que leyxou XI casaaes (...) segundo o Censual" - ADP, Cartório do Cabido, 1574 , f. $79 v$. 
diferentes: un cartulario y un censual ${ }^{19}$. En ninguno de ellos consta la fecha exacta, aunque comenzaron a ser elaborados a finales de la primera mitad del siglo XIV. Tratándose de dos libros dedicados a la organización y gestión documental, así como a la de los bienes y derechos de una determinada institución, podemos afirmar que el Censual do Cabido es una de las primeras manifestaciones claras de las prácticas de archivo de la canónica portuense, utilizadas en un contexto muy concreto de su historia ${ }^{20}$.

\section{El ARCHIVO DEL CABILdo A PARTIR DE FINALES DEL SIGLO XV}

El 24 de agosto de 1496, el obispo de Oporto Diogo de Sousa celebró un sínodo cuyo contenido sería publicado al año siguiente bajo el título Constituiçõees que fez ho senhor Dom Diogo de Sousa Bispo do Porto ${ }^{21}$. Estas Constituições contemplan todos los asuntos comúnmente relacionados con normativas de esta naturaleza, esto es, normas referentes a la disciplina del clero secular (particularmente los asuntos relativos a la curia pastoral), del clero regular y de los laicos, así como de las normas relacionadas con la gestión del patrimonio eclesiástico. Es decir, careciendo de un carácter original, estas Constituições "están a la altura de su tiempo y constituyen un digno paralelo de otras con las mismas características referentes a diócesis ibéricas (...)"22. Pero incluso siguiendo los modelos legislativos contemporáneos, $\mathrm{y}$, eventualmente recopilando $\mathrm{y} / \mathrm{o}$ reproduciendo normativas ya en vigor en la diócesis de Oporto, las Constituições de Diogo de Sousa son extremamente relevantes para el estudio de la organización y gestión de la documentación diocesana (y no solamente de la capitular). La Constituição XLII, titulada Acerqua de se fazerem emventairo de todas as herdades das igrejas, explica lo siguiente:

Porquanto somos emformado que em nosso bispado há muitos mosteiros, igrejas e beneficios eclesiásticos que teem muitas herdades, casaes e posissõees, e por nom estarem em tombo bem declarado se emlheam e tiram aos ditos beneficios (...) mandamos aos dignidades, conegos e cabiido desta nossa igreja e bem assi a todollos dom abades, priores, abades e rectores de todo nosso bispado (...) ponham em emventario feito per mãao de notairo ou tabaliam (...) E faram dous emventarios, scilicet huum que tenham sempre em os mosteiros ou beneficios e outro mande aqui a esta nossa igreja do Porto a nós pera se meter no cartorio della e hi estar (... $)^{23}$.

19. Censual do Cabido da Sé do Porto 1924. Este libro se encuentra en fase de estudio y será publicado por Maria João Oliveira e Silva y Joana Lencart.

20. Sobre este códice y el contexto en el que surge véase Silva, 2013, pp. 183-200.

21. Actualmente existen dos ejemplares manuscritos: uno bajo el cuidado de la Biblioteca Pública Municipal do Porto y el otro en la Biblioteca do Palácio Ducal de Vila Viçosa. Son las primeras constituciones sinodales portugueses impresas. Sobre estos dos ejemplares y su impresor, Rodrigo Álvares, véase Matos 1997, pp. 9-30.

22. García Y García 1997, p. 39.

23. Synodicon Hispanum. II - Portugal 1982, pp. 386-387. La preocupación con la defensa de los derechos y de los bienes patrimoniales se encuentra en el origen de este tipo de legislación sinodal, 
Como se podrá concluir, el prelado portuense revela su preocupación en relación con la elaboración de inventarios de los bienes de todas las instituciones eclesiásticas diocesanas -incluyendo de lo cabildo catedralicio-. Aún señala la importancia de producir esos inventarios por duplicado para que uno de ellos pueda mantenerse en la institución de origen y el otro en el archivo de la Iglesia de Oporto. De la aplicación de esta normativa surge entonces una triple preocupación: organizar los documentos (con el objetivo de salvaguardar bienes y derechos diocesanos), acceder a la información (a través de inventarios específicos) e conservar con seguridad todos los documentos (con la elaboración de dos ejemplares, uno de ellos destinado al archivo de la Catedral). A partir de este momento, el archivo catedralicio pasó a ser un complemento de los archivos parroquiales "una vez que muchos de los documentos producidos en las parroquias (...) eran copiados en libros que también se conservaban en ellas" 24 .

El cumplimiento de esta legislación por parte del cabildo se puede comprobar por la existencia, aún hoy, de diversos inventarios, generales y parciales, de rentas y propriedades capitulares producidos a partir del siglo $\mathrm{XVI}^{25}$. Sin embargo, los responsables por el archivo capitular en seguida se dieron cuenta que no era suficiente producir este tipo de especies archivísticas, sino que sería necesario "estructurar lo antes posible un sistema de consulta que permitiese acceder a ellos rápidamente" 26 . Se desconoce el momento exacto en el que fueron elaborados los primeros inventarios del propio archivo. Sin embargo, es posible que ya existieran en 1542 y que hayan servido de base para la elaboración del Sumário das semtemças doações comtratos forães sprituras cartas dadas em favor da See do Porto e cabido della que estam no dito cartorio que se encuentra inserido en el Censual da Mitra do Porto ${ }^{27}$. En este Sumário están catalogados apenas 37 documentos, correspondientes a las tipologías enunciadas en el título del documento y un caderno de capitolos da clerezia. Por su antigüedad, no podemos dejar de mencionar dos de ellos, concretamente, el testamento da Rainha Dona Tareja em o qual estam todolos coutos do bispo e outras cousas y una donación de la Rainha

tanto en Oporto como en otras diócesis como, por ejemplo, la de Braga. A todo este respecto véase Marques 1995, pp. 303-312.

24. Ribeiro 2003, p. 296.

25. Como por ejemplo los siguientes tombos generales: Tombo de todas as rendas e propriedades da mesa capitular desta See do Porto, criticamente fechado en 1557 (ADP, Cartório do Cabido, 8) y Tombo de todas as rendas das igrejas e propriedades da mesa capitular desta See do Porto e das vidas em que estão: feitos por Manoel da Costa mestreschola da dita See aos 20 de Junho de 1577 (ADP, Cartório do Cabido, 9); y los siguientes tombos parciales: Copia do Tombo que em 1543 se fez das propriedades, terras e mais cousas pertencentes à igreja de S. Eulalia de Oliveira do Douro (ADP, Cartório do Cabido, Cartório do Arcediagado de Oliveira do Douro, 176), Livro intitulado do Tombo das cazas que o R.mo Cabido tem nesta cidade e dos foros e censos que se lhe pagão, de 1663 (ADP, Cartório do Cabido, 458). Un ejemplo del cumplimiento de la referida normativa por parte de una institución monástica lo constituye el inventario del archivo de Paço de Sousa, que data de las primeras décadas del siglo XVI (ADP, Convento de São Salvador de Paço de Sousa, 1, 82).

26. Marques 1995, p. 309.

27. Censual da Mitra do Porto de 1542, ff. 249-250. Este libro ha sido estudiado y publicado integralmente por Santos 1973. El referido "Sumário" se encuentra entre las páginas 537 y 540. 
Dona Tareja do couto do Peso da Regoa. Partiendo del principio que el primer documento es la carta de donación y de coto del burgo de Oporto, hecha por Doña Teresa al obispo Hugo, en 1120, y el segundo otra donación de la misma reina al mismo obispo hecha en 1127, nos deparamos con dos originales que en aquel momento se llevaban conservando en el archivo durante 400 años. Este echo comprueba lo que se mencionó en la introducción de este trabajo, esto es que, desde el momento de la restauración de la diócesis, la preservación documental fue una de las preocupaciones de los responsables por la organización y gestión de los bienes y de los derechos de la Catedral. Por otro lado, el número de documentos identificados parece muy reducido. Es posible que esta cuestión esté relacionada con el contenido de los mismos, con una elección deliberada de los ítems enumerados en el Censual da Mitra, teniendo en cuenta el propósito con el que se elaboró el libro.

Esta fuente también es importante para comprender el sistema de acondicionamiento de la documentación:

As quaes semtemças doações comtratos (...) estam todas na arqua que esta na casa e livraria do cabido em que estam todalas matricolas das ordeens que se deram no bispado de çimquoenta annos a esta parte $(. . .)^{28}$.

Obsérvese el detalle de que el cofre con la documentación estaba junto a la biblioteca del cabildo, confirmando ese compartir de espacio físico que como ya fue dicho se verificaba desde principios del siglo XIV. Este cofre tenia tres llaves: una en poder del obispo (o del vicario general durante las ausencias del prelado), otra en poder del canciller del cabildo y la tercera en manos del propio responsable por el archivo, el escribano de la cámara del obispado ${ }^{29}$. Este hecho comprueba que todavía no había entrado en vigor el sistema de separación de los archivos de la Mesa episcopal y de la Mesa capitular, que se verificaría más tarde.

\section{El ARCHIVO DEL CABILDO EN LOS SIGLOS XVI y XVII}

A partir de finales del siglo XVI el archivo del cabildo sufrió alteraciones tanto al nivel de su ubicación física como de su organización interna. En relación con el primer aspecto, la mudanza de instalaciones se encaja en las reformas realizadas en la Catedral durante el episcopado de Frei Marcos de Lisboa (1582-1591). De las alteraciones que se efectuaron resultó la construcción de la casa del cabildo y dentro de ella una secretaría y un archivo, este último situado sobre la capilla de Nossa Senhora da Piedade o de Santa Catarina, en el claustro de la Catedral. Debido a la falta de espacio el archivo se ordenó dentro de armarios empotrados. Esta situación aliada al problema de la humedad habrá contribuido para provocar daños en la documentación que allí se conservaba, tanto de la mitra como del cabildo, tal

28. Censual da Mitra do Porto de 1542, f. 539.

29. La puerta del archivo también tenía tres llaves, que estaban en poder del canciller y del portero del cabildo. 
y como declaran algunos testigos posteriores ${ }^{30}$. De hecho, internamente el archivo estaría organizado de forma binaria, es decir que, a pesar de la junción física, obispos y canónigos tenían la obligación de promover la organización y la gestión de los documentos de forma autónoma. Esto es lo que se deduce de las Constituições Sinodais de 1585, de Frei Marcos de Lisboa, donde se insta a la obligación de elaborar dos inventarios distintos (de donaciones, compras, contratos, sentencias, permutas y cousas perpetuas):

hum das cousas que pertencem à nossa Mesa Pontifical, que nós [obispo] mandaremos fazer \& outro das cousas que pertencem à Mesa Capitular das dignidades \& Cabidos (sic) da dita $\mathrm{Se}^{31}$.

Sin embargo, según lo que se ordenaba en las Constituições de 1496 y nuevamente en las de 1585, tanto estos inventarios como todos aquellos que llegasen a la Catedral provenientes de las iglesias y de los monasterios de la diócesis deberían ser guardados no cartório da nossa Sé32.

El inventario más antiguo que se conoce hasta hoy, surgido en el periodo comprendido entre 1654 y 1674, describe el archivo del cabildo cuando este se encontraba encima de la capilla de Nossa Senhora da Piedade. El criterio de elaboración de este índex se basó en la localización, organización y contenido de los cuatro cajones y del almario que formaban el cartório en ese momento ${ }^{33}$. El primero de estos cajones estaba situado da parte do paço do bispo, el segundo debaixo do almario da banda do paço do bispo y el tercero y cuarto debaixo do almario do meo (pera a parte do claustro). Dentro de cada uno de ellos se almacenaban diversos fajos de distinta envergadura (maços, macetes y macinhos), hasta un total de 26 que estaban distribuidos de la siguiente manera: en el primer cajón los fajos del 1 al 3, en el segundo del 4 al 10, en el tercero los fajos del 11 al 14 (y fajos pequeños del 1 al 18), en el cuarto cajón los fajos del 15 al 19. En el almario $1^{\circ}$, dentro do almario do meo em cima à mão direita, estaban los fajos del 20 a 26. Estos manojos, haces y fajos estaban atados con fio de barbante. Relativamente a la lógica de su organización, en el primer cajón se guardaban los que contenían documentos relacionados con los votos de Santiago y con las localidades de Válega, Ovar y Cabanões; en el segundo cajón se archivaban los documentos de Lobão, Canedo, Vila Nova, Gaia, Canidelo, así como los de las comarcas de Santa Maria da Feira y Maia; en el tercer cajón entraban los documentos de Penafiel, Sobretâmega y algunos otros relacionados con bienes localizados en otros obispados; en el cuarto cajón se conservaban los documentos relativos a la ciudad de Oporto. Como se puede ver, nos deparamos con un sistema de organización que privilegiaba la

30. Según se verifica en referencias del siglo XVIII (Gonçalves 1970, p.11).

31. Constituições Synodaes do Bispado do Porto 1585 , f. $94 \mathrm{v}$.

32. Constituições Synodaes do Bispado do Porto 1585, f. 95.

33. ADP, Cartório do Cabido, 2. El inventario es necesariamente posterior a 1654, una vez que en la lista secuencial de los plazos y de otros documentos es esa la fecha del último registro, debiendo ser anterior a 1674 visto que los registros de esa fecha corresponden a letras y manos diferentes y posteriores. 
localización geográfica de los bienes y de las propiedades capitulares. El armario primero obedece a un criterio de organización diferente, que tiene como base la tipología documental y donde se guardaban documentos relacionados con testamentos, censos, cumplimientos de aniversario, privilegios y sentencias. Este armario también contenía la biblioteca del cabildo y dentro de ella, en el almario do meo, se guardaba el referido Censual do Cabido.

A partir de finales del siglo XVIII esta organización sufrió una alteración radical. Sin embargo, aún hoy se encuentran algunos vestigios del sistema anterior, concretamente, las cotas que remiten a los referidos fajos. En uno de los casos fue posible reconstruir prácticamente todo el fajo 20, que se encontraba en el armario 1 con el título: Pergaminhos e papeis toquantes a fazendas e censos que pessoas diversas deixarão a este cabido, que contenía un total de 47 documentos $^{34}$. Em varios documentos existen también indicaciones como: Quem desatar este maço torne-ho atar ${ }^{35} \mathrm{o}$ Esta este maço no almario do meo a mão direita em cima ${ }^{36}$.

Las referidas alteraciones de organización podrán ser un reflejo de las normas emanadas de las Constituições Sinodais de João de Sousa, fechadas en $1687^{37}$. Efectivamente, en el Libro 4, Título V (Do Archivo publico \& guarda dos papeis de cada igreja) el espacio físico del archivo es redefinido y el acondicionamiento de los documentos se transforma por primera vez en objeto de regulación, afirmando:

que na nossa Sé haja lugar \& casa separada \& dentro nella haja almarios ou caixões com repartimentos de boa madeira bem lavrados pera nelles se meterem \& guardarem os ditos livros, pergaminhos \& mais papeis em repartimentos \& caixões separados $(. .$.$) \& em cada hum dos ditos repartimentos \& caixoens da banda de$ fora se porá rotolo, ou letreiro, pera se saber, cujo he \& conforme o ditto titulo se guardem nelle todos os livros, pergaminhos, papeis, documentos, escrituras, emprazamentos, doações, testamentos, contratos, sentenças, collações de benefícios \& erecções de igrejas ${ }^{38}$.

Además de estas alteraciones también resulta evidente una reorganización interna del archivo que pasa a contar con una división ternaria, debiendo de existir:

caixões separados \& distintos de modo que os tocantes à Mesa Pontifical estejão em parte \& caixão separado, \& os da [Mesa] Capitular em outra, e os communs a huma \& outra mesa em outra ${ }^{39}$.

34. Actualmente estos mismos pergaminos se encuentran dispersos por dos Livros de Originais, el libro 1678 (que contiene 24 de estos documentos) y el libro 1686 (que contiene otros 21), estando en falta apenas dos: los números 15 y 45.

35. ADP, Cartório do Cabido, Livros dos Originais, 1687, ff. 11 e 65.

36. ADP, Cartório do Cabido, Livros dos Originais, 1680, f. 7, aludiendo al antiguo fajo 23, al que servía de portada, una vez que contiene el título "Privilegios". Contiene pergaminos de privilegios concedidos al cabildo.

37. Constituiçoes Synodaes 1735.

38. Constituiçoes Synodaes 1735, p. 393.

39. Constituiçoes Synodaes 1735, p. 393. 
Es decir, a la separación ya en vigor, relativa a la documentación de la mitra y del cabildo, se unió a partir de aquel momento un nuevo apartado en el archivo dedicado a la documentación común de ambas mesas. En estas Constituições se añade aún la obligación de elaborar inventarios de los archivos de cada una de las tres mesas y de un Index Geral no qual se escreverão distintamente por alfabeto todos os papeis que nelles estiverem ${ }^{40}$. Como ya se mencionó, el índex del archivo del cabildo, elaborado entre 1654 y 1674, se basó en la descripción de los cajones y del armario que componían el archivo, razón por la cual no se siguió el criterio alfabético impuesto por las Constituições de 1687. Actualmente no se conserva ningún inventario del archivo capitular que siga ese criterio, aunque es posible que haya existido, como ocurre con otras instituciones eclesiásticas de la diócesis de Oporto y de las cuales hoy todavía se conservan ${ }^{41}$.

\section{El ARChIVo DEL CABILDO EN LOS SIGLOS XVIII y XIX}

La organización en cajones del archivo canonical se alteró por completo entre finales del siglo XVIII y principios del XIX, coincidiendo con su traslado para otro emplazamiento. De hecho, varios datos indican que durante las últimas décadas del Setecientos el archivo pueda haber sido objeto de una reforma en su reorganización. Esta reestructuración parece coincidir con los cambios que se realizaron en la Catedral a principios del siglo XVIII, que llevaron a la construcción de la nueva casa del cabildo entre 1717 y 1722. En el tercer piso de esta casa se planeó una división específica para albergar "la casa del archivo" ${ }^{2}$. La urgencia en la creación de este nuevo espacio tenia que ver con la extrema humedad del local donde se guardaba anteriormente (en las dependencias del cabildo situadas en el claustro, sobre la capilla de Nossa Senhora da Piedade) qué cauzou muito damno aos papeis do archivo, principalmente estando este metido em almarios nas paredes por não haver área capaz para se por fora dellas ${ }^{43}$. De esta manera, en la nueva sala del archivo, os papeis e os libros fueron colocados em huas estantes de madeira de castanho fichadas e apartadas das paredes, según el reporte que fue elaborado después de las obras ${ }^{44}$.

Un inventario hecho en 1820 refleja estos cambios en el archivo capitular. En ese momento estaba distribuido por armarios (que serían las referidas estanterías de madera cerradas), de la letra $A$ a la $F$, teniendo algunos de ellos entre 1 y 3 bancos. Los armarios seguían una organización cuya línea de orientación era el tipo de documento en causa y no la proveniencia geográfica del mismo. Es decir

40. Constituiçoes Synodaes 1735, p. 393.

41. Véanse, por ejemplo, los inventários de 1643 de los monastérios de São Simão da Junqueira, São Martinho de Crasto y Santa Maria de Vila Nova de Muia (ADP, Convento de São Simão da Junqueira, 1. 55).

42. Gonçalves 1970; Ferreira, 1924, pp. 307-308; Botelho 2006, pp. 30-31.

43. Gonçalves 1970, p. 11.

44. Publicado por Basto 1940, p. 262. 
que se alteró el esquema que había sido aplicado hasta entonces. De esa manera, los armarios de la letra $A$ contenían varios itinerarios, forales, así como diversos tombos y asientos, el Censual do Cabido (que en el siglo XVII se guardaba en la biblioteca) y los 30 libros de pergaminos designados como Livros dos Originais. En los armarios de la letra $B$ se guardaban varias decenas de libros y copias de libros de concesiones a plazo; en los de la letra $C 95$ libros de sentencias; en los de la letra $D$ libros de sentencias, regalías, patronazgos y de inquirições de genere; en los de la letra $E$ los documentos relativos a portagens y votos; en los de la letra $F$ documentación variada, entre ellos libros de demandas del cabildo, libros de diezmos y de fábrica.

Además de este local de conservación, el cabildo guardaba documentos en el llamado cartório pequeno do claustro, como se comprueba por el inventario elaborado en $1827^{45}$. Este segundo archivo podrá haber estado situado en la zona occidental de la antigua casa del cabildo, es decir, sobre la capilla de Nossa Senhora da Piedade, que solo fue demolida en 1930-1940 durante las obras de restauración $^{46}$. Sin embargo, resulta más probable que se localizara en el pequeño claustro superior $^{47}$, también designado en los documentos por varanda, donde entre 1717 y 1718 se abrió una puerta de entrada para el archivo, en la extremidad sur occidental $^{48}$. En este inventario del archivo pequeño se refiere la existencia de cuatro estanterías, de las letras $A$ a $D$. En la $A$ se archivaban los libros de la hacienda; en la $B$ los de portagem y diezmos; en la $C$ algunas docenas de libros y fajos relativos a las cuentas, recibos y gastos; en la estantería $D$ se archivaban los libros de jubilaciones, sinecuras y mensualidades.

El análisis de los inventarios de los siglos XVII y XIX muestra un cambio claro en la manera como los canónigos archivistas pensaban en su acervo. De este modo, si en los Seiscientos el criterio de organización se fundamentaba en la localización geográfica de los bienes y de las propiedades descritas en un determinado libro, papel o pergamino, a partir de los Setecientos el criterio orientador de la organización del archivo pasó a ser el de carácter administrativo. A pesar de todo, este cambio en el paradigma de organización parece que no fue lo más consensual. De hecho, el mismo responsable por la elaboración del inventario de 1820 , el Padre Luís de Sousa Couto, al referirse al itinerario y al inventario que describían el archivo según la disposición antigua, dice lo siguiente: Mostra [el itinerario] a antiga ordem em que esteve o cartório. Sendo hum Índex Geral delle na maior parte geographico. Oxalá se tivesse até hoje conservado no mesmo sistema, añadiendo:

Mostra bem [el itinerario] o antecedente e antigo estado do cartório, e como ele se faz inútil quando tudo no cartório mudou de face. Sendo para lamentar que

45. ADP, Cartório do Cabido, 3 .

46. Gonçalves 1970 , p. 66. Aunque supuestamente este espacio estuviese destinado apenas a los beneficiados y a los capellanes, para vestir y guardar sus sobrepellices.

47. Este claustro se remontaba al siglo XVII, al periodo de sede vacante de 1647-1659. Gonçalves 1970 , pp. 56-57.

48. Gonçalves 1970 , p. 57. Basto 1940, p. 233, que data la construcción de este claustro en 1719. 
tanto trabalho, como o que se empregou em fazer os roteiros, e reduzir a livros os antigos maços de papeis e pergaminhos, só tenha servido para fazer complicado um cartório tão compreensível $(. . .)^{49}$.

El mismo Padre Luís de Sousa Couto refuerza aún su crítica diciendo: ...a multiplicidade de trabalhos mal dirigidos no arranjo do cartório (...) não tem de modo algum multiplicado, antes complicado as utilidades que deveriam resultar de tais trabalhos $(. . .)^{50}$. Es decir, a principios del siglo XIX, a los ojos de sus responsables, el archivo del cabildo parece haber sufrido un retroceso en la organización considerando el estado en que se encontraba anteriormente.

Con la publicación el 20 de abril de 1911 de la Lei da Separação do Estado das Igrejas $^{51}$ y la creación de comisiones administrativas en todas las catedrales, iglesias y capillas, el archivo de la Catedral fue dividido. Una parte de él fue enviada a la Biblioteca Municipal do Porto y otra parte para el Arquivo da Comissão Auxiliar da Administração dos Antigos Bens Cultuais, hasta que fue incorporado al Arquivo Distrital do Porto, lo que ocurrió entre 1932 y $1997^{52}$. Para comprender los periplos del archivo del cabildo durante la primera mitad del siglo XX es necesario localizar los inventarios y la documentación que los acompaña, elaborada durante los distintos procesos de mudanza de la institución depositaria. Solamente de esta manera será posible trazar con más rigor la evolución del arquivum capitular desde las primeras referencias medievales hasta la contemporaneidad.

\section{CONSIDERACIONES FINALES}

Anticipando o siguiendo las normativas promulgadas en las diferentes Constituições Sinodais y a través de referencias indirectas y/o de documentos concretos, ha sido posible acompañar la evolución del archivo de la Catedral y, más concretamente, del archivo del cabildo a lo largo de varios siglos. Los datos expuestos permiten concluir que la preservación de los documentos (en pergamino o en papel) y de los libros (de copia, de registro u otros), a la par de la necesidad de crear espacios adecuados para su custodia y de la definición de prácticas de conservación de los acervos, se afirman como una preocupación constante de la canónica portuense a lo largo de las centurias. También permiten verificar las alteraciones en las formas de pensar y de organizar la documentación, aunque sea imposible comprender totalmente las razones inherentes a esos cambios de actitud con relación al archivo. De hecho, es muy probable que se hayan desarrollado instrumentos de gestión y de pesquisa documental, como inventarios parciales y generales que, con el tiempo, se tornaron "obsoletos" e, por ese motivo, "inútiles" y "descartables".

49. ADP, Cartório do Cabido, 1 , ff. $7 \mathrm{v}$ e 8.

50. ADP, Cartório do Cabido, 1, ff. 8 e 9.

51. Sobre esta ley véase, por ejemplo, Miranda 2013, pp. 399-420.

52. Puede verse una breve descripción de este proceso en Almeida 1935, pp. I-VIII. 
Sin embargo, a pesar de los esfuerzos efectuados, diversos factores, tales como las sucesivas mudanzas de ubicación del archivo, la falta de condiciones y lo inadecuado del mismo, las prácticas archivísticas dañosas, la incuria humana, los desastres naturales o la suma de varios de estos factores, acabaron por provocar la pérdida de decenas de documentos que se elaboraron en épocas bastante anteriores, así como daños en otros tantos. Uno de estos casos concretos es el desaparecimiento de los sellos. El inventario de 1820, al que ya aludimos, indica la existencia de un saquito de estopa con el título: Selos de pergaminhos que se encadernaram. En relación con esta bolsita el autor del inventario, en tono de desahogo, dice: e melhor fôra desaparecer, para perecer com elle a memoria de huma barbaridade tal e que se não póde desculpar ${ }^{53}$. El tiempo acabaría por satisfacer su deseo porque, de hecho, este saquito desgraciadamente ya no existe. Pero, sin embargo, a pesar de todos estos "percances", la verdad es que la documentación conservada por el cabildo a lo largo de los siglos es fundamental para que hoy podamos estudiar esta institución, sin lo cual sería básicamente imposible. Esta situación contrasta, por ejemplo, con lo que sucede con relación al estudio de los obispos y del ejercicio de sus funciones, una vez que la documentación que sirve de soporte se encuentra conservada, en una grande mayoría de los casos, en los fondos monásticos. Aún falta elaborar la historia custodial del archivo de la mi$\operatorname{tra}^{54}$, que como se verificó, estuvo umbilicalmente ligado al archivo del cabildo durante varias centurias. En un futuro sería muy interesante estudiar ese archivo, sus paralelismos y sus diferencias con relación a su congénere capitular, para que sea posible comprender las prácticas archivísticas y la organización general de los acervos bajo la responsabilidad de los hombres de la Catedral de Oporto a lo largo de tantos siglos.

\section{BiBLIOGRAFÍA}

Almeida, José Gaspar de (1935), Inventário do Cartório do Cabido da Sé do Porto e dos Cartórios Anexos, Porto.

Basto, A. Magalhães Basto (1940), “A Sé do Porto. Documentos inéditos relativos à sua igreja", Boletim Cultural da Câmara Municipal do Porto, III / 2, pp. 230-270.

Botelho, Maria Leonor (2006), A Sé do Porto no século XX, Lisboa.

Censual do Cabido da Sé do Porto: Códice membranáceo existente na Biblioteca do Porto, (1924), Grave, João (ed.), Porto.

Clanchy, M. T. (1993), From memory to written record. England 1066-1307, Oxford.

53. ADP, Cartório do Cabido, 1, f. 9.

54. Este archivo se encuentra parcialmente conservado en el Arquivo Distrital do Porto. Véase una descripción de la historia custodial y archivística de este fondo en https://pesquisa.adporto.arquivos.pt/details?id=483145 
Constituiçoes Synodaes do Bispado do Porto novamente feitas, e ordenadas pelo Illustrissimo, e Reverendissimo Senhor Dom João de Sousa... propostas e aceitas em o Synodo Diecesano (sic), que o dito Senhor celebrou em 18 de Mayo do anno de 1687, (1735), Coimbra.

Constituições Synodaes do Bispado do Porto ordenadas pelo muyto illustre... senhor Dom frey Marcos de Lisboa, bispo do dito bispado \&c. Agora nouamente acrecentadas com o Estilo da Iustiça, (1585), Coimbra.

Costa, Avelino de Jesus da (1980), “Arquivos eclesiásticos portugueses. Origem e evolução”, Dicionário de História da Igreja em Portugal, vol. I, Lisboa, pp. 6-44.

Cunha, Maria Cristina Almeida (2005), A Chancelaria Arquiepiscopal de Braga (1071-1244), Galiza.

Ferraz, Francisco Manuel Teixeira (2008), A Casa da Moeda do Porto nos finais da Idade Média, Porto.

Ferreira, José Augusto Ferreira (1924), Memórias archeológico-históricas da cidade do Porto (Fastos episcopais e politicos) (século VI- século XX), tomo II, Braga.

García y García, Antonio (1997), “As Constituições Sinodais de D. Diogo de Sousa de 1496 (ed. Porto 1497)", Constituiçõees que fez ho senhor Dom Diogo de Sovsa B[is]po do Porto. Porto, na oficina de Rodrigo Álvares, 1497, Lisboa, pp. 31-37.

Gomes, Saul António (2007), In Limine Conscriptionis. Documentos, chancelaria e cultura no Mosteiro de Santa Cruz de Coimbra (Séculos XII a XIV), Viseu.

Gonçalves, Flávio (1970), A construção da actual Casa do Cabido da Sé do Porto, Porto.

Homem, Armando Luís de Carvalho (1982), "Da vedoria da fazenda ao bispado do Porto - a carreira de D. João Afonso Aranha", Humanidade. Revista trimestral da Associação de Estudantes da Faculdade de Letras da Universidade do Porto, 1, pp. 7-14.

Marques, José (1995), Sínodos bracarenses e renovação pastoral, Braga.

Matos, Manuel Cadafaz de (1997), "D. Diogo de Sousa, as Constituições Sinodais do Bispado do Porto (1497), alguns aspectos relacionados com o impressor Rodrigo Álvares e características técnicas da sua obra", Constituiçõees qve fez ho senhor Dom Diogo de Sovsa B [is]po do Porto. Porto, na oficina de Rodrigo Álvares, 1497, Lisboa, pp. 9-30.

Miranda, Jorge (2013), "Sobre a Lei de Separação do Estado da Igreja de 1911", Estudos dedicados ao Professor Doutor Nuno José Espinosa Gomes da Silva, vol. I, Lisboa, pp. 399-420.

Paiva, João Pedro (2000), “Constituições Diocesanas”, Azevedo, Carlos Moreira (coord.), Dicionário de História Religiosa de Portugal, vol. II, Lisboa, pp. 9-15.

Ribeiro, Fernanda (2003), O acesso à informação nos arquivos, vol. I, Lisboa.

Santos, Cândido Augusto Dias dos (1973), O Censual da Mitra do Porto: subsídios para o estudo da diocese nas vésperas do Concílio de Trento, Porto. 
Santos, Maria José Azevedo (1994), Da Visigótica à Carolina. A escrita em Portugal de 882 a 1172, Lisboa.

Santos, Maria José Azevedo (2001), “As condições de conservação dos documentos e dos livros em Portugal (séculos XII-XIV)”, Estudos de Diplomática Portuguesa, Lisboa, pp. 237-242.

Silva, Maria João Oliveira e (2013), A escrita na catedral. A chancelaria episcopal do Porto na Idade Média, Lisboa.

Synodicon Hispanum. II - Portugal, (1982), García y García, Antonio (dir.), Madrid. Vereaçoens. Anos de 1390-1395. O mais antigo Livro de Vereações do Município do Porto existente no seu arquivo, (s/ano), Basto, A. de Magalhães (ed.), Porto. 